\title{
SEASONAL VARIATIONS IN THE FAT CONTENT OF THE FLOUNDER, PLEURONECTES FLESUS L.
}

\author{
By Douglas P. Wilson, M.Sc.
}

Naturalist at the Plymouth Laboratory

(Text-figs. I-5)

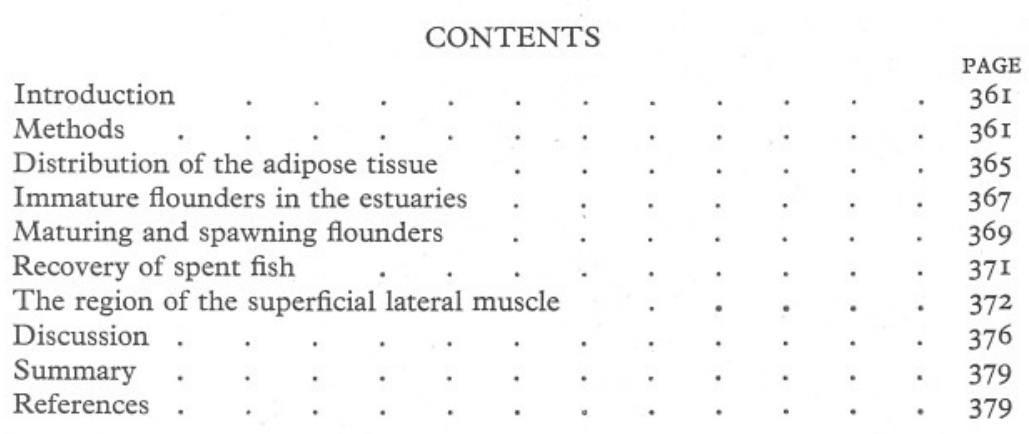

\section{INTRODUCTION}

In only a few fishes has any attempt been made to trace variations in the fat content from season to season and during the spawning period. Of the economically important herring, however, a great many seasonal fat analyses have been made, and more than one species of salmon has received attention from this point of view. So far as I am aware little has been done along similar lines for any of the bottom-dwelling flat fishes. When, therefore, there arose an opportunity of examining a plentiful supply of flounders, about which a good deal of other relevant information would be available, it was decided to concentrate on this species. The flounders in question were obtained by Mr P. H. T. Hartley during his investigations into the fisheries of the Tamar and Lynher estuaries. I am greatly indebted to him for his kindness in passing them on to me after he had weighed and measured them, noted the sex and maturity and removed the stomach of each fish. He subsequently supplied me with copies of his records which have proved invaluable.

\section{METHODS}

The fat content of a fish has sometimes been estimated approximately by visual judgement, as in assessing the quality of herrings by the amount of intestinal fat (ister) seen on opening the body cavity (Hjort, I9I4; Bjerkan, 1917). Occasionally judgement has been made from frozen sections cut from 
selected regions of the body and stained by one of the fat stains. This was the method mainly employed by Greene in his important work on the storage of fat in the muscular tissue of the king salmon, Oncorhynchus tschawytscha. Some investigators have preferred the method of chemical analysis; in this connexion can be mentioned the work of Johnstone (1915, 1918) and of Bruce (1924) on the Manx herring. Johnstone partly confirmed his results by cutting paraffin sections of portions of the muscular tissue, thereby demonstrating variation in the quantity of adipose tissue present. As it is not usually the practice to analyse chemically the whole of one fish, and it is always difficult if not impractical to deal with large numbers in this way, the chemical method may be no more efficient in demonstrating seasonal or ontogenetic variations in fat content than is the histological method, provided that the species treated in the latter way is one which gives a clear picture of the fat when cut and stained. On the other hand, the histological method can demonstrate only fat which is in such a form as to be readily stainable, and it does not allow of the calculation of calorific values.

In the present work histological technique has been used throughout. It was early realized that the cutting, staining and mounting of frozen sections takes up too much time to allow a really large number of fish to be examined. A much simpler technique was therefore devised and one that gave a better fat picture for each fish. The method consisted of cutting a slice $\mathrm{I}-2 \mathrm{~cm}$. thick across the fish at its widest part midway between head and tail. Prior to cutting, the fish were hardened in 10 \% formalin for at least several days. The slice was rinsed in $50 \%$ alcohol and immersed in a solution of Scarlet Red (Sudan IV) in equal parts of $70 \%$ alcohol and acetone contained in a tightly stoppered jar. After $20 \mathrm{~min}$. to half-an-hour it was removed from the stain, washed in $50 \%$ alcohol and then preserved in $5 \%$ formalin. For the purpose of preservation formalin is not ideal and does not keep the sections in as good a condition as does glycerine. It will, however, keep them for a few weeks and sometimes months without much deterioration of the staining, and the slices can always be restained to some extent. When large numbers of such slices of fish have to be preserved glycerine is almost prohibitive on account of its cost. I have not noticed any difference in result between neutral and non-neutral formalin.

The method enabled fairly large samples of fish to be handled expeditiously, for a number of slices could be stained at one time. It was found unnecessary to take more than one slice from each fish. A series of slices down a fish all gave similar fat pictures.

The appearance of typical slices is illustrated in Fig. I. Various regions would stain bright red and be large or small in area according to the amount of fat and adipose tissue present. In a fat fish areas roughly triangular in shape showed up distinctly among the muscles of the bordering fins. A bone, sliced across, generally showed more or less fat in and around it. The picture varied a little, of course, with the level of the cut, whether, for instance, it went 

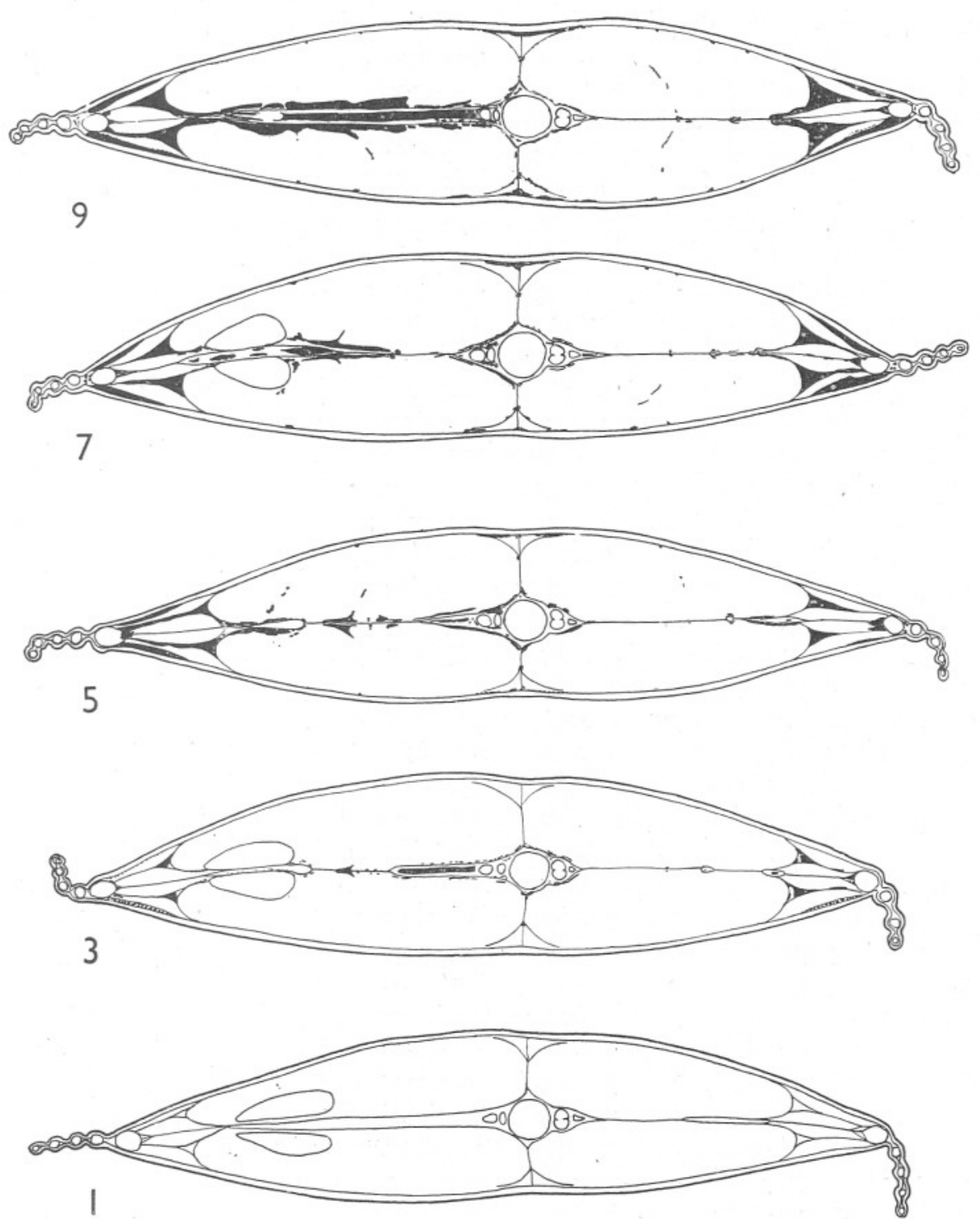

Fig. I. Diagrammatic representations of transverse slices of the flounder midway between head and tail to show the relative amounts of fat in the five main arbitrary degrees as follows: I, none; 3, little; 5, medium; 7, fat; 9, very fat. In this figure degrees I, 3 and 7 are illustrated by female fish, 5 and 9 by male fish. The fish selected as typical for the purposes of this illustration were all about $20 \mathrm{~cm}$. long. The figures are drawn by projection in an episcope, the fat which is stained deep red in the actual specimens being here shown as black. 
through the middle of a vertebra or passed between two of them. Variation in the level of the cut, however, never affected the general appearance of fatness; it did not expose so much more or so much less fat as to make a fish appear fatter or leaner than it would if sliced in another plane. The two faces of a slice always corresponded closely although they would rarely be cut at the same vertebral level. In judging fatness both faces of a slice were taken into consideration. After some experience it became easy to allot each fish to one of nine arbitrary degrees of fatness. Five primary degrees were chosen, none (degree I), little (3), medium (5), fat (7), and very fat (9); between these are the intermediate degrees $2,4,6$ and 8 . The five primary degrees are diagrammatically illustrated in Fig. I drawn from actual slices selected as typical, and optically projected by an episcope so that the outlines of the fat areas could be accurately traced. These drawings, together with actual type specimens, were used for comparison when assessing a sample of newly stained slices.

The accuracy of the method just outlined was checked from time to time by reassessing samples of fish the original records of which were not remembered. It always happened that not less than $80 \%$ of the fishes comprising the sample were given the same degree as before; the remainder would be placed one degree higher or lower, about half of them higher and about half of them lower. Very occasionally an odd fish would be moved two degrees up or down the scale of nine. Thus the method was well within the limits of error which could be allowed.

The main results based on the large slices were supplemented by cutting frozen sections from as many fish as possible. Large pieces of tissue were removed from the pigmented upper side half-way between head and tail. The pieces were generally obtained from large slices which had been previously cut and stained. The tissue was taken in the region of the lateral septum, extending some way on either side and down to the vertebral column. From each piece of tissue generally three, sometimes more sections were stained and mounted. Some were also cut from the region of the dorsal and anal fins after removal of the bones.

For cutting, the tissue was surrounded by an aqueous solution of gelatine $(5 \%)$ and the sections allowed to fall into a dish of the same solution kept just melted by gentle heat. Selected sections were stranded on clean slides, cooled and hardened first in formalin vapour and then in $5 \%$ formalin. The sections thus stuck to the slides were stained in Scarlet Red dissolved in equal parts of $70 \%$ alcohol and acetone. The sections were permanently mounted in glycerine sealed by glycerine jelly and "Murrayite". They have kept very well to date.

The sections were cut $150 \mu$ thick. Thinner sections were useless as the fat cells are relatively large and most of the fat is lost when their membranes are ruptured. By cutting thick sections fat loss was relatively reduced. The sections were thin enough for easy observation by transmitted light. 


\section{Distribution of the Adipose Tissue}

In this paper attention is confined to the fat and adipose tissues in and around the edible muscular portions of the flounder, and to some extent of its skeleton. The head and viscera are neglected.

Adipose tissue is developed in definite regions. The largest and most striking are clearly visible in a stained slice across the body of the fish; they are the fatty regions of the dorsal and ventral unpaired fins. The muscles to thefin rays are packed around with fatty tissue filling up the spaces which might otherwise be left between them. In a skinned fish which has been preserved in formalin, or in one that has been boiled, this adipose tissue is distinguishable from the whiter muscles by its yellow brown colour. This colouration seems to have misled Stirling (I886) into describing the tissue as red muscle, both in the plaice and in the flounder. In really fat fish much fat is deposited in these regions, padding out the edges of the fish so that they feel plump between the fingers. On the other hand a lean fish, particularly one which has lost all its fat at spawning, feels thin and even looks emaciated where the median fins join the body. In such a fish the adipose tissue is in a soft and collapsed condition owing to the withdrawal of the fat it formerly held.

There is generally a little fat between the skin and underlying muscles. Where the lateral septum joins the skin there is often a considerable accumulation which in transverse section (Fig. 2 A) frequently appears as a roughly triangular area bisected by the septum itself. There are similar deposits of fat where the myocommata reach the skin (Fig. 2 B). Adipose tissue extends down the myocommata in the region of the superficial lateral muscle and is often well developed where the myocommata join the lateral septum. Where the myocommata pass through the deep lateral muscle adipose tissue is generally absent, but in fat fish a little fat is deposited here and there.

The skeleton is a fat depot of some importance, particularly the vertebral column. The spongy parts of the vertebrae and their hollows are frequently heavily laden with fat, and so are the grooves and canals of the neural and haemal spines. Adipose tissue is often present around the bones. The bones of the skull may also be laden with fat.

Groups of fat globules are present in the skin among the chromatophores, but the quantity of fat so stored is very small in comparison with that in the depots already described.

Fat is distributed in a closely similar manner in many flat-fishes. Several specimens of each of the following species have been examined. Pleuronectes platessa; P. limanda; P. microcephalus; Rhombus laevis; Lepidorhombus whiff; Arnoglossus laterna; A. imperialis; Solea vulgaris. It is also very similarly distributed in Zeus faber. 

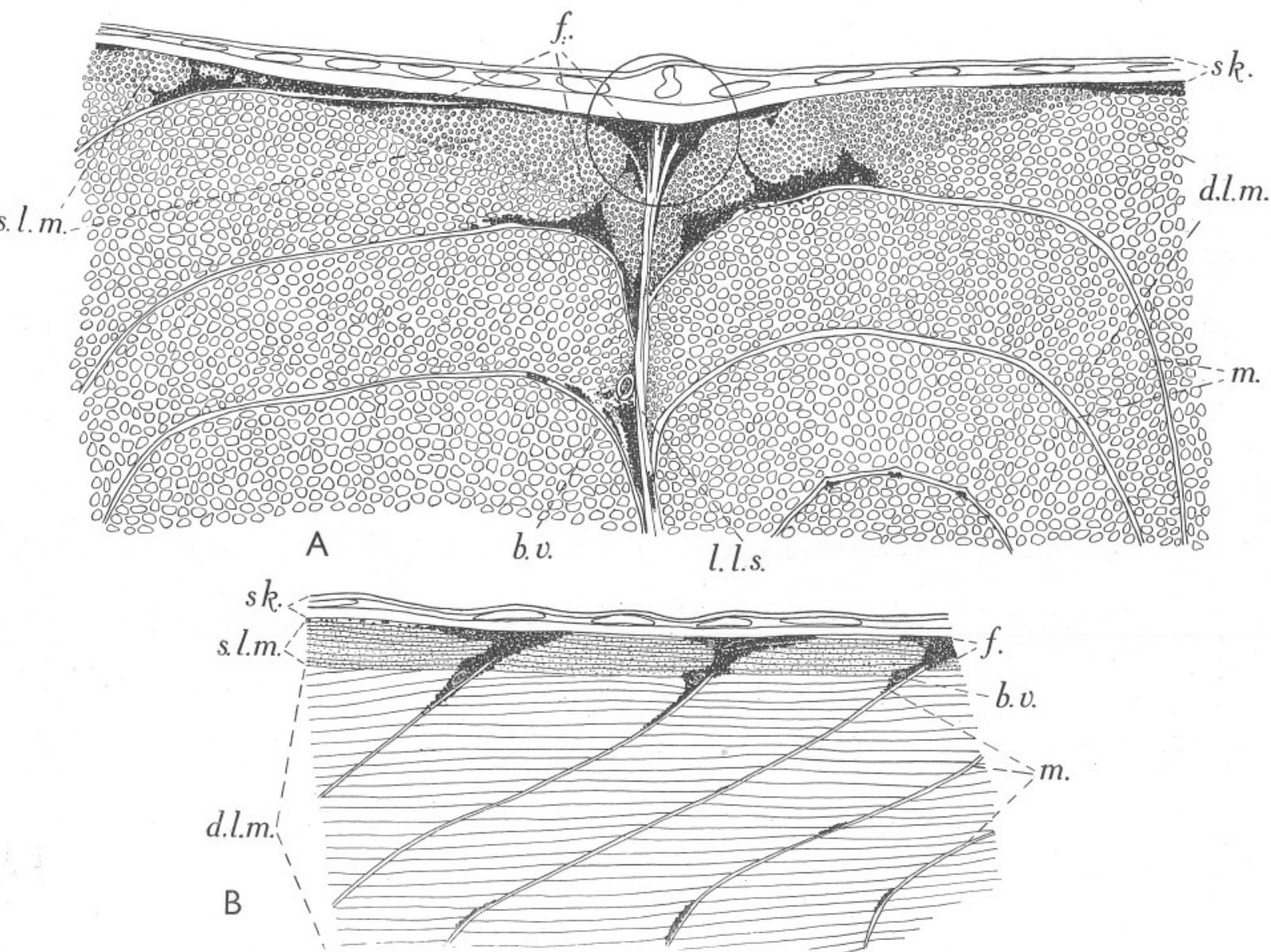

Fig. 2. Semi-diagrammatic representations of frozen sections of the muscular tissues close to the lateral line, midway between head and tail, on the pigmented side of the flounder. $\times 5$. Fat shown in black. The circle indicates the region shown in greater detail in Fig. 5. A. Transverse section from a female caught at sea in February I937. The fish was $35.7 \mathrm{~cm}$. in length and was placed in fatness degree 8 . Intramuscular fat was very plentiful in the superficial lateral muscle. B. Longitudinal section some little distance from the lateral line septum. This is from a male caught at sea in February I938. The fish was $28.8 \mathrm{~cm}$. long and was placed in fatness category 6 . Intramuscular fat was very plentiful in the superficial lateral muscle. b.v. blood vessel; d.l.m. deep lateral muscle (musculus lateralis profundus); $f$. fat in adipose tissue; l.l.s. lateral line septum; $m$. myocommata; sk. skin; s.l.m. superficial lateral muscle (musculus lateralis superficialis). 


\section{IMMATURE FLOUNDERS IN THE ESTUARIES}

The growth and life history of the flounder in the Tamar and Lynher estuaries is discussed by Hartley (1939). The immature fish feed and grow in the estuaries for several years before they go down to the sea to spawn. These immature fish formed the bulk numerically of the catches investigated. The fatness of these immature fish was followed from February 1937 to February I938, over five hundred fish being examined during this period. In addition

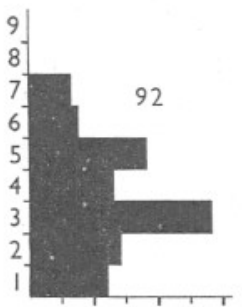

1937 FEB

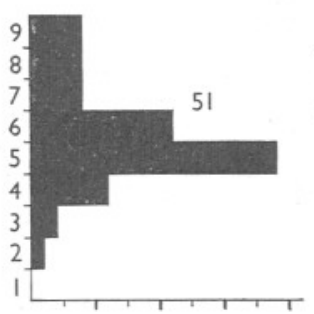

1937 OCT

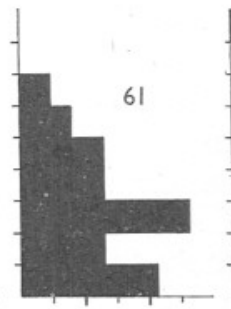

MAR

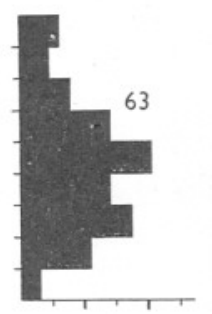

NOV

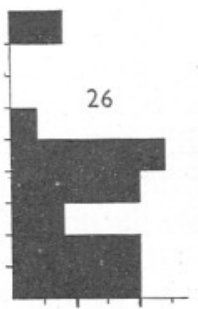

APL

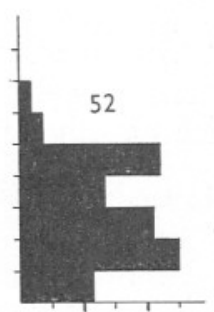

DEC

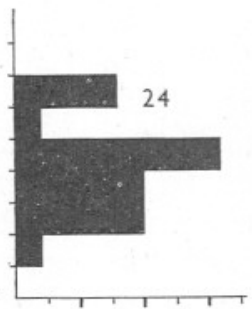

JUN - JUL

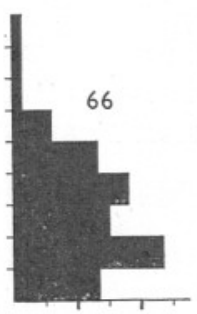

1938 JAN

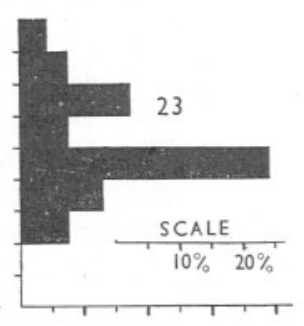

SEP

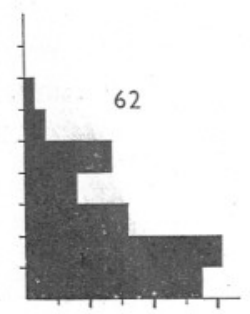

FEB

Fig. 3. The fatness of immature flounders caught in the estuaries. The ordinates are the arbitrary degrees of fatness explained on p. 364 and illustrated in Fig. I. The abscissae are percentages. The number inserted in each figure gives the actual number of fish on which it is based.

some small exploratory samples were examined prior to February I937; as far as they go they fit into the sequence here described. The results for males and females are combined since no significant difference was found between them.

The monthly results are given in the form of diagrams (Fig. 3). The fish were sliced and stained by the method already described. The diagrams give the percentage number in each fatness group. The number of fish on which each diagram is based is indicated in the figure.

It is at once obvious that in February 1937 the majority of the flounders had a medium (degree 5) or less than a medium amount of fat in their tissues; I2 \% had none. By March the percentage with none had increased to rather more than twenty-one and the sample as a whole was a little less fat than in the preceding month, although the difference is but slight; allowing for the experimental error inherent in the method it is perhaps not significant. The 
first week in April showed little change; the sample was a small one in which two large immature but very fat females probably give an undue prominence to degree 9 in the diagram. As explained by Hartley (1939), it was difficult to catch flounders during the summer and the samples taken then were all small. Only one fish was caught during May; it was of medium fatness (degree 5). The immature fish of June and July are combined in the one diagram. It is notable that in no fish caught during these months was fat entirely absent, while the general fatness of the sample was higher than before. In August a very few fish were caught but it is worth recording that of the four immature ones obtained three were fat (degree 7) and one medium to fat (degree 6). In September and October immature flounders reached their maximum fatness for the year. It is apparent from the diagrams that the majority were of medium fatness (degree 5) and over, a striking contrast to the condition of February, March and April fish. In November fatness was on the decline, and once again a few fish were found with no visible fat at all. December and January fish were on the whole definitely lean, while in February 1938 the leanest sample of the series was obtained, over half the fish having either no fat at all or very little indeed.

It is possible to work out a mean degree of fatness for each monthly sample: these means are presented in the first column of Table I. Again it will be seen that the immature fish fatten from March to September and October when the maximum is reached and then steadily lose fat until the following February.

Table I. Mean Degrees of Fatness of Immature Flounders

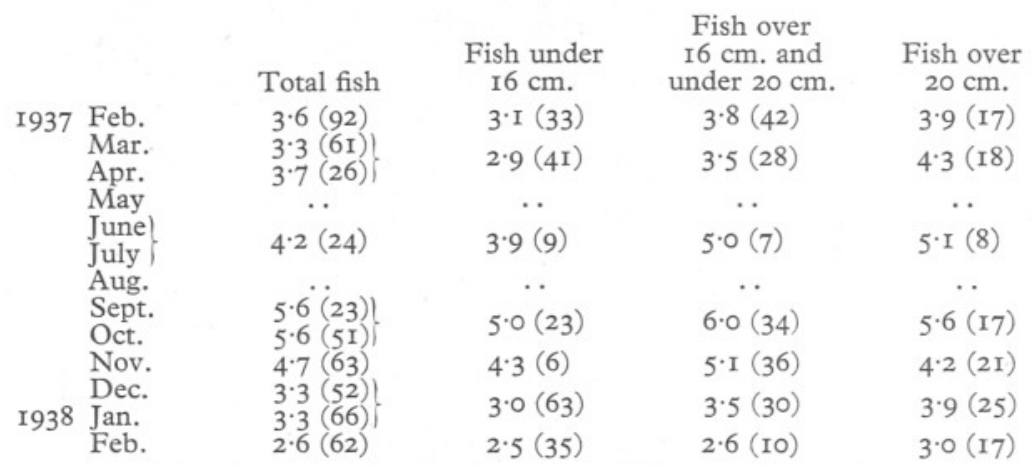

The numbers in brackets give the actual number of fish on which each mean is based.

The size range of the immature fish was considerable. Most of them were over Io $\mathrm{cm}$., but less than $20 \mathrm{~cm}$. in length. A few were less than $10 \mathrm{~cm}$. long. Of those which exceeded $20 \mathrm{~cm}$. only a very small number were longer than $25 \mathrm{~cm}$., the largest of all generally being female.

In order to ascertain whether fatness varies to any extent with size, the fish have been grouped into three classes according to length. The limits of each size group are somewhat arbitrarily selected, but a limit at $16 \mathrm{~cm}$. divides almost 
equally the yearly total of fish less than $20 \mathrm{~cm}$. long, although it will be seen from Table I that in any one sample there are usually more of one length class than of the other. It is not as a rule until they are longer than $20 \mathrm{~cm}$. that flounders mature and go down to the sea. The mean degree of fatness was calculated for each size group for each month, or for two months combined. These figures are given in Table I.

It will be observed that though there is little to choose between the relative fatness of the three size groups, the under $16 \mathrm{~cm}$. group are consistently leaner than the $16-20 \mathrm{~cm}$. fish, and in all but one month (November) leaner than the fish over $20 \mathrm{~cm}$. The latter have a slightly higher mean than the $16-20 \mathrm{~cm}$. fish except in the combined September and October groups and in November. Although the significance of this difference is uncertain as the numbers of fish were small, there is nevertheless the possibility that a proportion of the fish over $20 \mathrm{~cm}$., which would previously have been ranked as immature, are in the period September to November sufficiently far advanced in maturity to be then recognized as maturing flounders and would therefore no longer be counted among the immatures. Such fish would be likely to be among the fattest in the sample and their removal would bring about a lowering of the mean.

On one point the means for the three length groups are quite definite; they demonstrate conclusively that the annual cycle of fatness in immature fish over Io $\mathrm{cm}$. long takes place irrespective of size.

\section{Maturing and Spawning Flounders}

Maturing and spawning flounders leave the Tamar and Lynher estuaries early in the year and by the end of February only immature fish remain. It is possible to distinguish the ripening fish, or at least some of them, during the preceding summer: in the later months of the year this can be done with greater certainty as the gonads become more swollen. Ripening estuarine fish are always relatively large, the females generally exceeding $25 \mathrm{~cm}$. in length, though the males are often smaller than this. The fatness records for maturing estuarine flounders are presented graphically in Fig. $4 a-c$, and the means based on the same figure are given in Table II. As the total number

\section{Table II. Mean Degrees of Fatness of Maturing and MATURe Flounders}

Estuarine fish:

Mean degree of fatness

June, July and August 1937 ...

November and December 1936 and 1937

January and February 1937 and $1938 \ldots$ Sea fish:

February 1937 and r938 $\quad \ldots \quad \quad \ldots$

$\begin{array}{llll}\text { March I937 and I938 } & \ldots & \ldots & \ldots \\ \text { April I937 and I938 } & \ldots & \ldots & \ldots\end{array}$

Females returned to the estuaries after spawning:

May-August 1937 $\begin{array}{lll}\cdots & \ldots\end{array}$

$\begin{array}{ll}7 \cdot 0 & \text { II } \\ 7 \cdot 0 & 30 \\ 6 \cdot 1 & 33 \\ 6 \cdot 5 & 75 \\ 4 \cdot 7 & 62 \\ 2 \cdot 4 & 29 \\ 6 \cdot 4 & 7\end{array}$

No. of fish

II

33

75
62

29

7 
of fish was rather small two years are combined. There was no marked difference between corresponding months of the two years when each year was considered separately.

If the fatness of these ripening fish be compared with that of immature flounders for the corresponding seasons it will be seen that they are much fatter. The mean for the summer months is $7 \cdot 0$, a figure never reached by the immature fish. It is conceivable that this may be exceeded during September and October at which time immature fish are fattest. Unfortunately all large

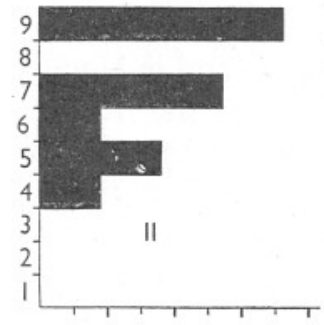

a. $\mathrm{UUN}-\mathrm{AUG}$

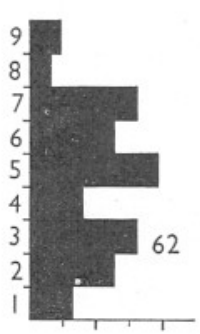

e. MAR

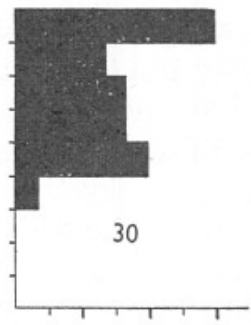

b. NOV-DEC

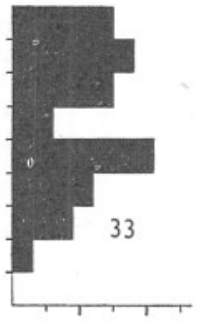

c. JAN - FEB

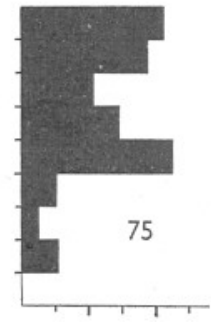

d. FEB

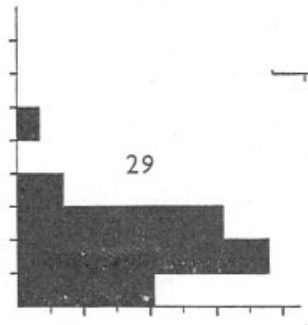

f. $\quad$ APL

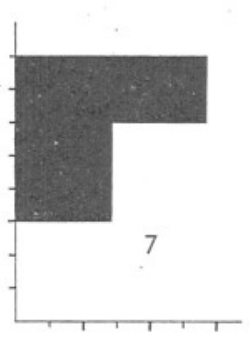

g. MAY - AUG

Fig. 4. The fatness of maturing and spawning flounders. $a-c$, fish caught in the estuaries; $d-f$, fish caught at sea; $g$, females caught in the estuaries after spawning. $a$ is based on fish caught in I937 only; $b$ on fish caught in I936 and I937; $c-f$ on fish caught in I937 and I938; $g$, on fish caught from May 29 to August 9, I937. The scales are as in Fig. 3.

fish caught during those months were required for marking experiments and there are therefore no fat records available. The mean is, however, still $7 \cdot 0$ during the last two months of the year, a period when immature fish rapidly lose fat. By January and February, however, there has been a slight decrease in the fatness of those maturing fish which have not yet moved down to the sea.

A few flounders were caught at sea during January, but it was not until February that they were at all numerous in the trawl. While some of these would have come from the estuaries a short time before capture, it is possible that some had been in the sea since at least the preceding season. Unfortunately we know nothing of the life of such fish in the sea; as Hartley (I939) points out, flounders are rarely taken in the trawl out of the breeding season. 
Ripe and ripening sea-fish during February generally have plenty of fat in their tissues although a few are quite lean. The mean is high (6.5), for these fish as a whole are relatively fatter than are immature fish at their best during the late summer months, while they are, of course, very much fatter than are immature fish during February. This fat is, however, rapidly used up during the spawning period so that in April, by which time the fish are quite ripe or have already spawned, sea flounders are very lean indeed. The loss of fat is so rapid that the adipose tissue presents a collapsed appearance, sections showing crumpled cell walls enclosing no fat at all or only a few droplets. It will be noticed that in two months the figure for mean fatness falls from 6.5 to $2 \cdot 4$, whereas in immature fish it takes at least four months for the mean to fall through the smaller range of $5 \cdot 6-2 \cdot 6$.

It would be instructive to find out if possible whether the loss of fat during the spawning period is at all accelerated during the presumably strenuous act of shedding eggs or sperm. The figures denoting mean fatness for February, March and April (Table II) include partly spent and spent fish. If we work out the mean fatness of these spawning and just spawned fish we get the following figures, the number in brackets indicating as usual the actual number of fish on which each mean is based: February, 5 (I); March, 4 (I8); April, 2.4 (9). Ignoring February when only one spent fish was obtained it will be seen that while the figure for March is appreciably lower than the mean for all March sea fish combined, that for April is exactly the same. From this last result it seems likely that the decrease in fatness is a process not particularly accelerated by exhaustion during spawning. The lower mean for spent and partly spent fish in March may perhaps be simply due to these fish being a little in advance of the others in maturity, or as the difference is small it may not actually be significant.

\section{RECOVERY OF SPENT FISH}

Relatively few spent fish are caught in the sea, and these are nearly all obtained in March and April. After April they are not caught at all when trawling at sea, perhaps because they move too close inshore (Hartley I939). Some of them perhaps die shortly after spawning. A few females, but apparently no males, make their way back to the estuaries and may there be caught in the tuck-nets, when they are easily recognized as spent by the condition of the gonad. Seven such females have been examined; they were caught on different dates between and including May 29 and August 9, I937. Their mean fatness was high (see Table II and Fig. $4 g$ ); the loss at spawning had evidently been made good rapidly. The histological difference between their tissues and those of ripe fish is dealt with below. 


\section{The Region OF the Superficial Lateral Muscle}

Frozen sections of the superficial lateral muscle region of the dark side halfway between head and tail were cut from one hundred and thirty-eight flounders selected as typical specimens of both sexes caught at all seasons of the year, both mature and immature fish. These were sufficient to give some idea of the histological distribution of the fat in this important region and of its seasonal changes.

The distribution of the subcutaneous fat and that on the myocommata as seen in these sections has already been described (p. 365). The fat is present in the form of liquid globules each enclosed within a fine membrane, the wall of the fat-storing cell. When the cell is fully loaded the wall is difficult to distinguish, but when the cell loses fat, as during spawning, it is more readily visible (Fig. $5 c$ ). Large globules may be as much as $125 \mu$ in diameter, but most of them are of various sizes smaller than this. In very fat fish the globules all tend to be large (Fig. $5 a$ ) and are so closely packed as to be distorted by pressure against one another. In leaner fish the globules are on the whole smaller and not so numerous, but nevertheless they may be closely packed and distorted (Fig. 5 b), the difference in the amount of fat between a lean fish and a fat one being due as a rule mainly to the smaller amount of adipose tissue in the former and not so much to a wider spacing of the globules (compare $a$ and $b$ in Fig. 5). This is particularly true at the season of maximum fatness, but it does not hold good for fish which have recently lost much fat from their tissues. At the end of the spawning season the globules are often spaced apart and, because they are no longer pressed against one another, they round up within their cells (Fig. 5 c). In fish which have suffered severe fat loss globules are not only much reduced in size, some being minute, but they are often rather widely spaced apart due to the complete absorption of many others (Fig. $5 e$ ). The absorption of the fat brings about a collapse of the adipose tissue cells which are crushed and crumpled between skin and muscles. Immature

Fig. 5. Semi-diagrammatic representations of the muscular and fatty tissues cut transversely near the junction of the lateral line septum with the skin. The area shown is indicated approximately by the circle in Fig. $2 \mathrm{~A}$. The sections were stained in scarlet red and mounted in glycerine. For full explanation see text. $a$, from a ripening male. Tamar estuary November I937. Length $21.5 \mathrm{~cm}$. Fatness degree 9. A moderate amount of intramuscular fat was present but is not shown in the figure. $\times 22 ; b$, from a ripening male. Tamar estuary November 1937. Length $2 \mathrm{I} \cdot 0 \mathrm{~cm}$. Fatness degree 5. A little intramuscular fat was present but is not shown in the figure. $\times 22 ; c$, from a ripe female, caught at sea February 1938. Length $36.6 \mathrm{~cm}$. Fatness degree 5, showing evidence of considerable fat absorption. Intramuscular fat was plentiful in most fibres of the superficial lateral muscle. A few clear fibres are seen. $\times 92 ; d$, a few fibres of the superficial lateral muscle showing arrangement of the intramuscular fat droplets. From a ripening female caught at sea in February 1937. Length $35.7 \mathrm{~cm}$. Fatness degree $8 . \times 350$; $e$, from a ripe female caught at sea in March I937. Length $34.9 \mathrm{~cm}$. Fatness degree 5 . Fat globules small and scattered, evidence of much absorption having taken place. $\times$ I 4 ; $f$, from a female which had returned to the Tamar estuary after spawning. Caught June 1937. Length $34.7 \mathrm{~cm}$. Fatness degree 7 . No intramuscular fat was present. $\times$ I4. 

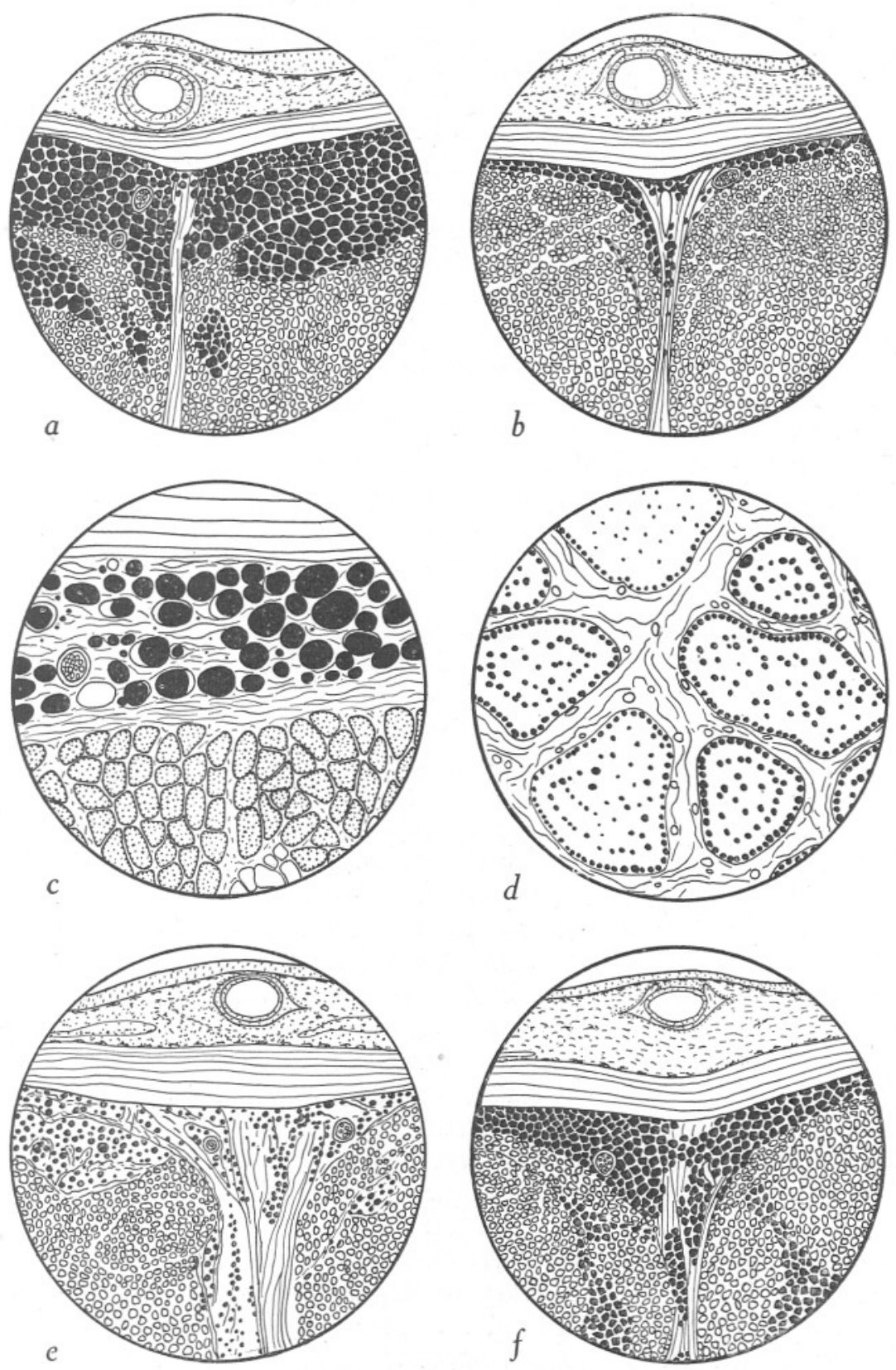

FIG. 5. 
estuarine fish at the end of the winter show similar evidence of fat reduction, but to a less extent, the globules then not being on the whole quite so large and tightly packed as in September and October. In some individuals during February and March the globules are tiny, rounded and well separated. Thus the seasonal and spawning variations in general fatness can be followed, as might perhaps have been expected, in the histology of the adipose tissue of a particular body region.

Although histological investigation has been concerned chiefly with the superficial lateral muscle region, sections of the fat reservoirs between the dorsal and anal fin muscles have been cut from a few individuals. The condition of these depots appears to correspond exactly with that of the adipose tissue under the skin. In fish which have lost much fat during the spawning period the fat globules are all very small, rounded and widely scattered among empty and crumpled cells, just as they are in the mid-lateral region. It has already been remarked that loss of most of the fat in this region of a formerly fat flounder can be detected in the entire fish (p. 365). The withdrawal of much of the fat leaves the tissue readily compressible between finger and thumb. This is still more easily observed while handling large slices across the middle of the fish.

Fat is withdrawn from the skeleton about the same time as from the other depots. On account of the difficulty of sectioning this region it has not been examined in histological detail.

At certain times and in certain individuals, fat droplets appear inside most of the fibres forming the superficial lateral muscle. In the king salmon (Greene, 1914) this muscle similarly carries drops of intramuscular fat, only in much larger quantity. This is in addition to a large quantity of intermuscular fat between the fibres; the total amount of fat of both types being relatively enormous. In the flounder there is no intermuscular fat in either the superficial or deep lateral muscles, but the presence of intramuscular fat droplets at certain times is very interesting and merits attention. So far as I am aware, such intramuscular fat has been described only for the salmon. I have, however, seen fat droplets in large numbers in the fibres of the superficial lateral muscle of quite small specimens of the hake, Merluccius merluccius (L.). They do not seem to occur in the much fatter herring, but doubtless other fish will be found to possess them.

Intramuscular fat droplets are most strongly developed in sea flounders during the spawning period. The droplets are generally no more than 2 or $3 \mu$ in diameter and are frequently less, but occasionally in a few fibres, perhaps in different parts of the same fibre, they reach a larger size and may be as much as 7 or $8 \mu$ across; rarely they are larger still. A transverse section of a fibre (Fig. $5 d$ ) generally shows a ring of droplets immediately under the sarcolemma with others scattered rather uniformly in the main body of the fibre itself. Both in size and distribution within the fibre they correspond closely to the description Greene has given for the king salmon. 
During summer months no intramuscular fat is visible in the majority of estuarine fish, both maturing and immature. The cytoplasm of the muscle also takes up little or no stain, being clear and almost colourless in appearance in the preparations. In the autumn, however, this muscle sometimes stains pale pink with Scarlet Red and in some fish intramuscular fat droplets are to be seen. These droplets are very pale in colour, suggesting that when they first appear they contain little true fat. During the winter immature fish vary in condition; in some the cytoplasm is unstained, such fish having as a rule no intramuscular fat or at most very little. In others the cytoplasm stains pink and these fish generally have intramuscular fat droplets, occasionally in abundance. Maturing fish at this time nearly all show a pink staining of the cytoplasm and have fat droplets in the fibres, in a few individuals these are in large numbers. The concentration of intramuscular fat in the immature fish shows little or no increase beyond the winter condition, but in mature fish from the sea during February and March much of it is found, the droplets staining much more deeply at this time than before. The cytoplasm too is generally stained pink, often quite deeply. Only exceptionally in such fish is there no intramuscular fat. This condition of strongly stained cytoplasm and much intramuscular fat persists until after spawning. Even in fish which have lost most of the fat from their adipose tissue the superficial lateral muscle stains quite deeply and contains fat droplets in abundance. This fat is evidently not reduced in quantity while that from the adipose tissue is being used up. It is nevertheless soon lost; females which have returned to the estuaries after spawning show clear unstained cytoplasm (like most other summer fish) and no intramuscular fat-or at most only a trace. These latter fish are generally fairly fat, their adipose tissues being well laden with large globules closely crowded together (Fig. $5 f$ ). The absence of fat from their superficial lateral muscle fibres is therefore not due to lack of fatty materials at that time. The immature fish in the estuaries also lose their intramuscular fat about the same time.

The foregoing description of the intramuscular fat cycle is only a brief sketch of changes followed with the aid of a single stain; an insufficient number of fish have been sectioned for a complete account to be given. Microchemical investigation is desirable before attempting seriously to discuss its implications. It may be noticed, however, that while this intramuscular fat is most strongly developed in mature sea fish, and might possibly be related to the maturation of the gonads, it also appears in immature fish, although to a less extent, about the same time. Hartley (1939) has shown that there is sometimes to be observed a spurious ripening among immature flounders. The presence of intramuscular fat can also, of course, be correlated with temperature, and perhaps with other conditions of the environment as well. 


\section{Discussion}

We have seen that immature flounders are fattest at the end of the summer and leanest at the end of the winter. This refers to the population as a whole, for at any one time some fish are much fatter than others of the same size and sex. Sex appears to have little effect on general fatness, while there is only a slight tendency to greater fatness with increase in size. No doubt some individual flounders are naturally lean while others have an equally natural tendency to store fat in their tissues; this is probably to some extent independent of the amount of food consumed. It seems legitimate to assume, however, that after a period of intensified feeding lean fish will be fatter than usual and naturally fat fish very fat. During periods of starvation both types of fish may be expected to use up some or all of their fat reserves. With this idea in mind we can correlate seasonal variation in fatness with feeding.

Hartley has examined the stomach contents of the flounders used in these fatness determinations and he has shown (1939) that the immature fish have a marked period of fasting during the winter and that this fast is not completely ended until probably April. This period when little food is taken is that during which immature flounders lose much of their autumn fat. In the winter of I $937-8$ Hartley found that the fast began earlier than in the preceding year, and to this may perhaps be correlated the greater leanness in February 1938 as compared with February 1937. During the summer and until September feeding is most intense; it is at the end of this period that the immature fish are fattest.

Maturing and mature flounders behave differently for they continue to feed throughout the fasting period of the immature fish, only ceasing to take food during the spawning season in the sea. To these habits again fat content may be correlated, maturing flounders remain very fat until the end of the year and then show a rapid loss while breeding. During spawning a great deal of energy is probably expended in muscular and other activities; abstention from food at this time will cause a heavy demand upon the fat reserves, and, as we have seen, they are depleted very rapidly.

It might be expected that in maturing fish fat would be withdrawn from the tissues during maturation of the gonads, which in the female especially accumulate a great quantity of fatty substances. The fat for the gonads, however, may come from the visceral fat which has not been investigated during the present work. It should be remembered too that the fish are continually feeding while the gonads are filling. At any rate the gonads reach their full size before there is any loss of fat from the muscular regions. This is in agreement with what is known of the herring where it appears not improbable "that the metabolic demands of the growing gonads are met, in the first instance by the fatty reserves of the liver, while at a later stage the stores of mesenterial fat may be called upon. There is no evidence that the fat of the muscular tissue undergoes depletion, until shortly before the time of 
spawning" (Bruce, I924, p. 483). Johnstone (I918) found that in the herring maturation of the gonads is accompanied by an increased loading of the subdermal and intermuscular connective tissues with fat, and that this loading does not decrease until a short time before spawning and "after the major part of increase in mass of the gonads has taken place". As is well known, herring do not feed while spawning. More recently Channon and El Saby (1932) have shown that in maturing herring the muscle fatty acids continue to increase in amount after those of the liver and mesentery have begun to decrease.

Johnstone (1915, 1918) emphasized the importance of temperature as a factor in influencing variations undergone by the tissue fat. He showed the close correspondence between sea-temperature and rise and fall of fat content, and argued that temperature must be a factor in addition to the sexual cycle. Thus Clyde winter-spawning herring maturing in cooling water have a considerably lower maximum fat content than the Manx autumn spawners. He had little to say about feeding. The close correlation between fatness and feeding is discussed in a recent paper by Lovern \& Wood (1937). The facts are strongly reminiscent of those already pointed out for the flounder.

The effect of seasonal temperature variations on the flounder is probably reflected in the intensity of the feeding of immature fish. It is while the temperature is rising and during the period when it is presumably maximal that feeding is most intense, with a corresponding effect on the fat reserves. The winter fast begins while the temperature is falling. Maturing fish, on the other hand, continue to feed while the temperature is falling and any effect on them is not apparent.

With the immature flounder can be compared the immature plaice. Johnstone (I9I8) records that in plaice less than $30 \mathrm{~cm}$. long the weight per unit of length varies regularly with the sea-temperature, the plaice being heaviest for their length when the sea-temperature is maximal and lightest when it is minimal. Hartley (1939) has worked out a similar condition factor for the flounder and the same relation is apparent although he does not specially distinguish between immature and mature fish. Hartley's condition factors correspond fairly closely with the figures for mean fatness if due allowance be made for the fact that they are not tabulated on quite the same basis.

Bruce (1924) found that the fat content of herring muscle at any given stage of maturity is increased by age. Lovern (1938) has recently stated that the fat content of the freshwater eel "increases almost linearly with length, at any rate between certain limits". Bruce's and Lovern's findings are based on chemical analyses. It has been seen that in the immature flounder a size increase also brings about a slight general fattening as measured histologically. An insufficient number of mature fish are available for a good comparison to be made between their smaller and larger sizes. The figures that are available suggest that there is very little tendency to increased fatness with size.

Some further comparisons of the intramuscular fat of the flounder with that of the king salmon are of interest. It will be remembered that in the flounder 
fat in the fibres of the superficial lateral muscle is apparently not drawn upon while that of the normal adipose tissue is removed during the last stages of maturity (p. 375); it disappears last of all. In the salmon (Greene, I9I4) there is a very large load of intramuscular fat at the beginning of the long migration; this is gradually used up during the journey but is not completely removed and even at death a considerable quantity is still present. The deposition of fat in the superficial lateral muscle of the salmon begins in embryonic life and increases in amount up to the time of cessation of feeding. The deep lateral muscle on the other hand does not show fat droplets inside its fibres until the salmon ceases to feed early in the journey to the spawning grounds. These droplets thus appear at a maturity stage corresponding very roughly with that in the flounder at which the intramuscular fat develops in the superficial but not the deep lateral muscle. The droplets in the deep lateral muscle of the salmon maintain a relatively uniform distribution in the fibres until death. Greene infers that the fat in the fibres is utilized in the production of muscular energy expended during the migratory journey up river. He suggests that this intramuscular fat is maintained at its uniform distribution by a continual replenishment from the intermuscular fat depots and those of the adipose connective tissues which are depleted during the migration. He argues that with the cessation of feeding the products of digestion no longer reach the active musculature, and that there is then thrown into the deep muscle fibres a supply of fat adequate to the energy needs. Reference should be made to Greene's own paper for details of his hypothesis to which he devotes much space.

Comparing salmon and flounder it is evident that the superficial lateral muscle has a much greater potentiality to the deposition of fat droplets in its fibres than has the deep lateral muscle. In the salmon it early begins the accumulation of what eventually becomes a great store of fat; the deep muscle on the other hand does not have an intramuscular loading until very much later and it is never as great as that of the superficial muscle at its maximum. In the flounder the superficial lateral muscle is the only one of the two lateral muscles ever to acquire droplets of fat in its fibres. They are most strongly developed in mature fish, especially after cessation of feeding. They also occur in some immature fish and it may be significant that it is during or just after the winter fast that they are most numerous. In all classes of flounder during the summer when they are intensively feeding these droplets are almost entirely or quite absent. It may be that in all fishes the superficial lateral muscle has a greater tendency to store fat than has the deep lateral muscle. The fat may not always be detectable by histological techniques; it may be in a form recognizable only by chemical extraction. The fact that no droplets are to be seen in the fibres of any particular fish does not necessarily mean that there is no fat there at all. A seasonable comparison between superficial and deep lateral muscles of many types of fishes carried out biochemically and checked histologically might yield interesting results. 


\section{SUMMARY}

In the flounder adipose tissue forms a padding between the muscles to the dorsal and ventral fins. A little is present under the skin, more especially where the lateral line septa and the myocommata meet the skin. In addition a quantity of fat is associated with the skeleton.

Immature flounders living in the estuaries of the Tamar and Lynher are fattest after intense feeding during the summer, and leanest after the winter fast.

Maturing flounders have a high fat content before going to sea to spawn. While in the sea during the spawning season, February to April, very little feeding takes place and there is a rapid drop in fat content. Spent fish are very lean.

Those females which return to the estuaries after spawning rapidly make good their fat loss.

There is considerable individual variation in fatness irrespective of seasonal and spawning variations.

Large fish tend to be slightly fatter relatively than small. General fatness does not appear to be affected by sex.

In some individuals the fibres of the superficial lateral muscle contain numerous fat droplets during the autumn and winter. They are not present as a rule during the summer. These intracellular droplets are a striking histological feature of mature sea fish during the spawning season.

\section{REFERENCES}

BJERKAN, P., I917. Age, maturity and quality of North Sea herrings during the years I9IO-I3. Rep. Norweg. Fish. Mar. Invest., Vol. III, No. I, pp. I-I I9.

BRUCE, J. R., I924. Changes in the chemical composition of the tissues of the herring in relation to age and maturity. Biochem. Fourn., Vol. xvIII, pp. 469-85.

Channon, H. J. \& El SABY, M. K., I932. Fat metabolism of the herring. I. A preliminary survey. Biochem. Fourn., Vol. XXvI, pp. $202 \mathrm{I}-34$.

GreENE, C. W., I9I4. The storage of fat in the muscular tissue of the king salmon and its resorption during the fast of the spawning migration. Bull. Bureau Fisheries Washington, Vol. xxxiII, pp. 69-138.

GREenE, C. W. \& GREENE, C. H., I9I4. The skeletal musculature of the king salmon. Bull. Bureau Fisheries Washington, Vol. xxxIII, pp. 2 I-59.

Hartley, P. H. T., I939. The Saltash tuck net fishery. A contribution to the ecology of estuarine fishes. (In Press.)

HJoRT, J., I914. Fluctuations in the great fisheries of northern Europe. Rapp. Proc.verb. Int. Cons. Explor. Mer, Vol. xx, pp. I-228.

Johnstone, J., I915. The fat content of Irish Sea herring. Proc. and Trans. Liverpool Biol. Soc., Vol. xxix, pp. 216-23.

I9I8. The dietetic value of the herring. Proc. and Trans. Liverpool Biol. Soc., Vol. xxxiI, pp. 85-I3I.

Lovern, J. A., I938. Fat metabolism in fishes. XIII. Factors influencing the composition of the depot fat of fishes. Biochem. Fourn., Vol. xxxII, pp. I2I4-24.

LOVERN, J. A. \& WoOD, H., I937. Variations in the chemical composition of herring. Fourn. Mar. Biol. Assoc., Vol. xxir, pp. 28I-93.

StIRLING, W., I886. On red and pale muscles in fishes. 4th Ann. Rep. Fish. Board Scot. for the Year 1885, pp. I66-7I. 